\title{
microSTAR ii
}

medical dosimetry system

- The advantage of using Reflection geometry (uses mirror) Pulse controlled LED emission makes the background noise low.

- The main advantage of the microSTARii is its software, and the microStar ii can choose the number of readings for one time (twice to 5times), also the software calculate those average automatically.

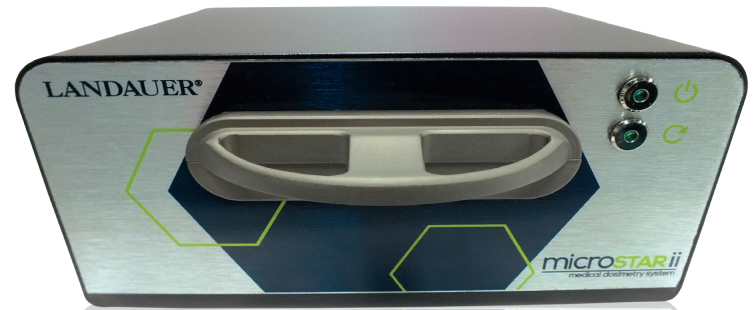

\section{Dosimeters}

The microSTARii can only read nanoDots.

\section{Size\&Weight}

Smaller and lighter than microStari.

Weight: $2.33 \mathrm{~kg}$
Software

Main focus is Medical dosimetry with patient info fields.

Reading Operation

Push the read button and automatic reading of dosimeters.

Software workflow

Reader screen is optimized for multiple readings \& reports.

LANDAUER
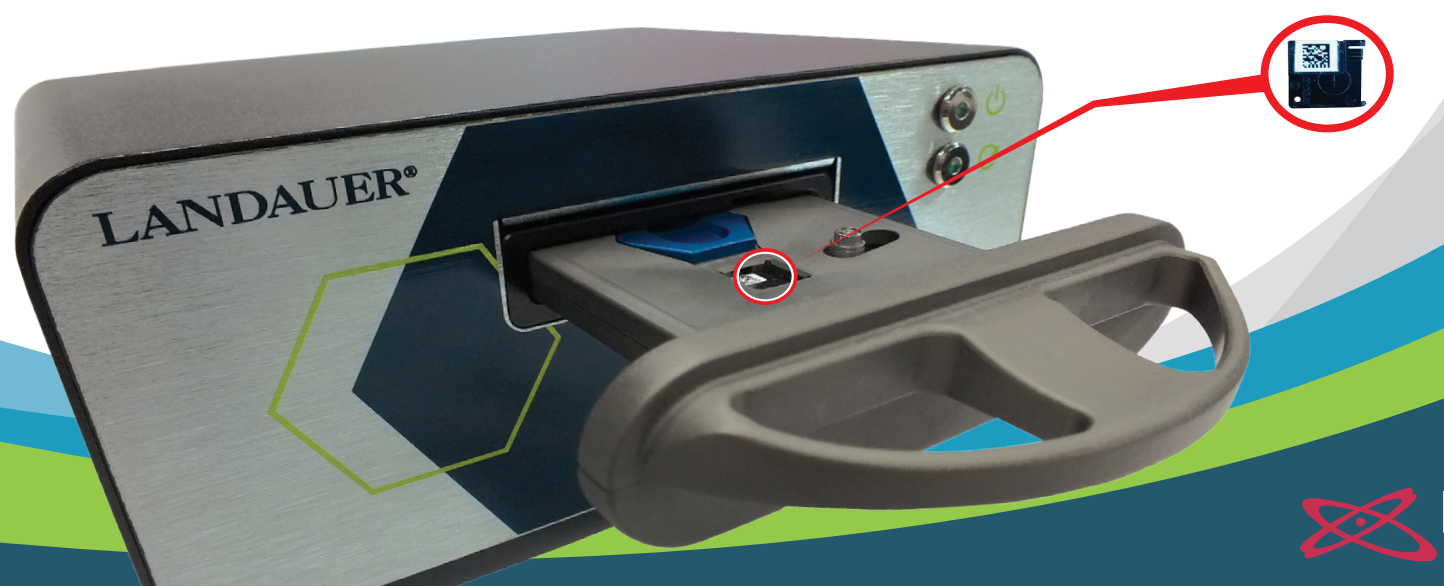


\title{
Development of a Web-Based Program for Cross- Calibration and Record Management of Radiation Measuring Equipment
}

\author{
So Hyun Park ${ }^{1}$, Rena Lee ${ }^{2}$, Kyubo Kim², Sohyun Ahn ${ }^{3}$, Sangwook Lim ${ }^{4}$, Samju Cho \\ ${ }^{1}$ Department of Radiation Oncology, Jeju National University Hospital, Jeju University College of Medicine, Jeju, ${ }^{2}$ Department of Radiation \\ Oncology, Ewha Womans University School of Medicine, Seoul, ${ }^{3}$ Department of Radiation Oncology, Kangwon National University Hospital, \\ Kangwon University College of Medicine, Chuncheon, ${ }^{4}$ Department of Radiation Oncology, Kosin University College of Medicine, Busan, \\ ${ }^{5}$ Department of Radiation Oncology, Ewha Womans University Medical Center, Ewha Womans University School of Medicine, Seoul, Korea
}

Received 17 April 2019

Revised 6 June 2019

Accepted 21 June 2019

Corresponding author

Samju Cho

(chosamju@gmail.com)

Tel: 82-2-2650-5337

Fax: 82-2-2654-0363
Purpose: To manage radiation measurement equipment, a web-based management program has been developed in this study.

Materials and Methods: This program is based on a web service and Java Server Pages (JSP) and employs compatibility and accessibility.

Results: The first step in the workflow has been designed to create accounts for each user or organization and to log in. The program consists of two parts: fields for listed instruments, and measurement information. The instruments for measuring radiation listed in this program are as follows: ionization chambers, survey meters, thermometers, barometers, electrometers, and phantoms. Instrument properties can be put in the recording fields and browsing for associated instruments can be performed. The main part of the program is the cross-calibration for each ion chamber. For instance, the ionization chamber to be used as a relative dosimeter can be registered by cross-calibration data with a reference chamber calibrated by an accredited laboratory. This program supports methods using the central axis transfer theory for cross-calibration for the ionization chambers. The reference and field ionization chambers were placed in a solid water phantom along the beam central axis at two different depths, and then the positions were switched. Each measured value was used for calculating the cross-calibration factor.

Conclusions: Because many instruments are used and managed in radiation oncology departments, systematic, traceable recording is very important. The web-based program developed in this study is expected to be used effectively in the maintenance of radiation measurement instruments.

Keywords: Radiation therapy, Web-based program, Record management, Cross calibration

\section{Introduction}

Nowadays intensity-modulated radiation therapy (IMRT) became the dominant method for delivering radiation therapy to patients and the safety of radiation therapy became essential. Therefore the importance of the record related to the radiation therapy to patients and the quality assurance (QA) are emphasized ${ }^{1,2)}$ In addition, the importance of calibration and record of radiation measurement instrument is also issued. The ionization chamber and the electrometers are the representative instrument requiring the calibration. And also the thermometers and the 
barometers, are needed to be calibrated. Many reports recommend that the quality assurance and the calibration of the instruments are to be performed periodically. ${ }^{3-5)}$ Especially, the annual quality assurance must be checked by using the calibrated instrument. The department of radiation oncology generally has many instruments of radiation measurement. However, to calibrate every instruments are difficult due to economic and calibration period reasons in most of clinics. Therefore, the protocols such as TRS398 recommend using cross calibrated instrument about reference calibrated by secondary standard dosimetry laboratory (SSDL). ${ }^{3)}$ Cross calibrated instruments also have the advantage of replacing the reference measurement instrument during calibration period. These instruments are important to consider traceability and easy management for efficient use. Each institution maintains its instrument through a separate form. Therefore, if the management system for radiation measurement instrument is easy to use and can be used integrally, it will not only be possible to cross-check the instrument by each institution, but also

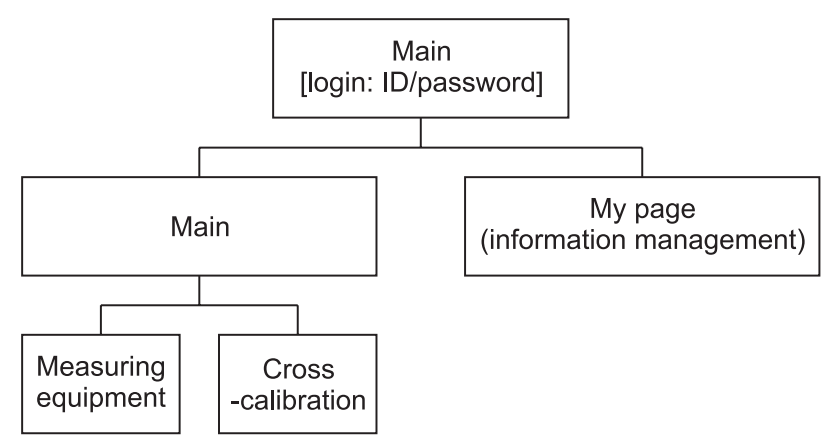

Fig. 1. Diagram of web-based program configuration. it will be easy to maintain.

Therefore, we developed web-based programs to simplify complex cross calibration and to maintain radiation measurement instrument.

\section{Materials and Methods}

\section{Development environment and configuration}

The program was built with JSP (Java Server Pages) language based on web service considering compatibility and accessibility. Developed program were composed of the session related to recording of measurement instrument and a cross calibration shown as Fig. 1 .

\section{The session of the measuring equipment}

In the Measuring Equipment session, every instrument listed its period of calibration, recording and management. Each instrument can be configured to be able to record certification, calibration reports and necessary information for each instrument.

\section{The session of the cross-calibration}

The central axis transfer method proposed by Luc Serré was applied for the cross calibration. ${ }^{6}$ The ionization chamber for field to be crossly used in clinical was calibrated by the ionization chamber for reference which was calibrated by accredited institution. We supposed the measurement environment as source-to-surface (SSD) of
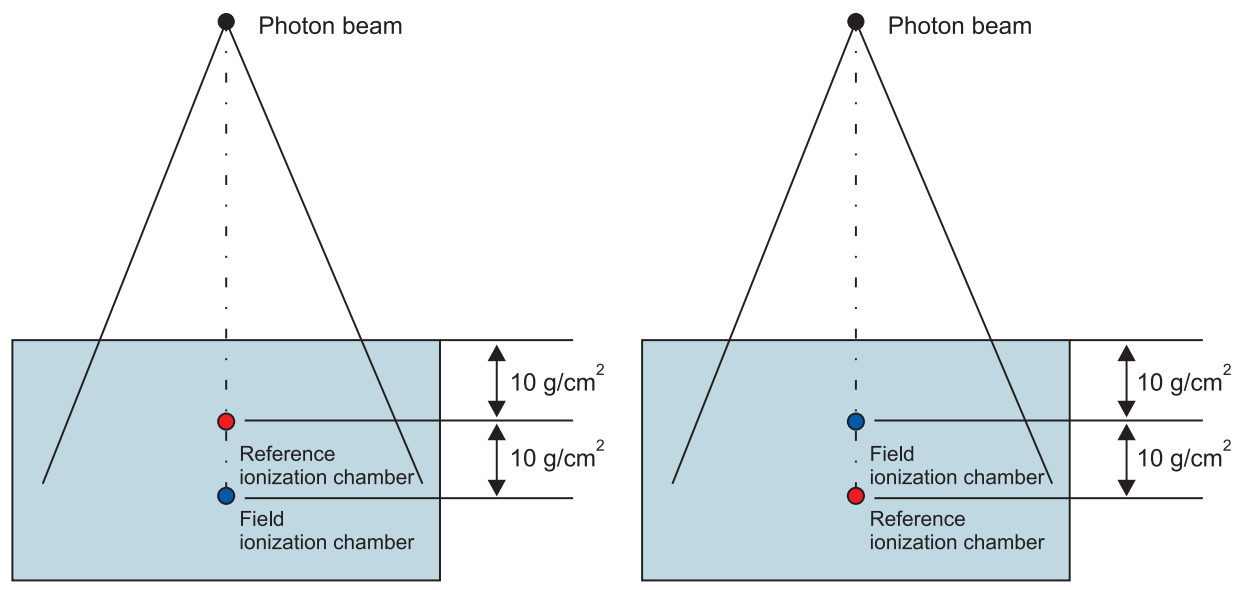

Fig. 2. The central axis transfer method, the positions of the reference and field ionization chambers are changed. The same MU is delivered for each condition. 
$100 \mathrm{~cm}$ and field size of $10 \times 10 \mathrm{~cm}^{2}$. The reference and field ionization chambers were respectively inserted along the beam central axis at two different depths in the Solid Water $^{\mathrm{TM}}$ phantom. Radiation doses of same monitor unit (MU) were irradiated twice and the measured values of each chamber were read and averaged. And then, the depth of both ionization chambers was switched and the process of previous irradiation and reading was repeated as shown Fig. 2. According to the theory of the central axis transfer, the absorbed dose to water calibration factor for the field ionization chamber is given by the following relationship:

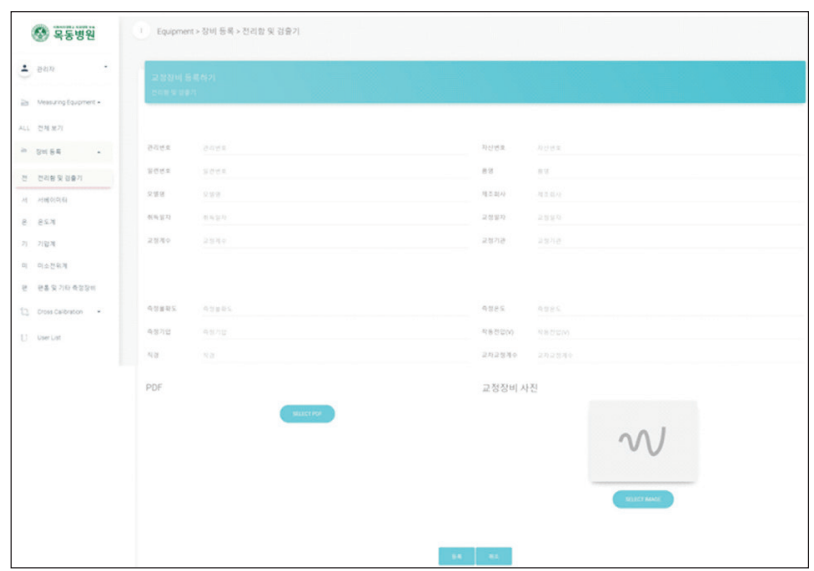

Fig. 4. The total list and the registration form of ionization chamber.

$$
\left(N_{D, W}^{60_{c o}}\right)_{\text {field }}=\left(N_{D, W}^{60_{C o}}\right)_{\text {ref }} \times \frac{\left(\bar{M}_{c}\right)_{\text {ref }} \times\left(k_{Q}\right)_{\text {ref }}}{\left(\bar{M}_{c}\right)_{\text {field }} \times\left(k_{Q}\right)_{\text {field }}}
$$

Eq.1
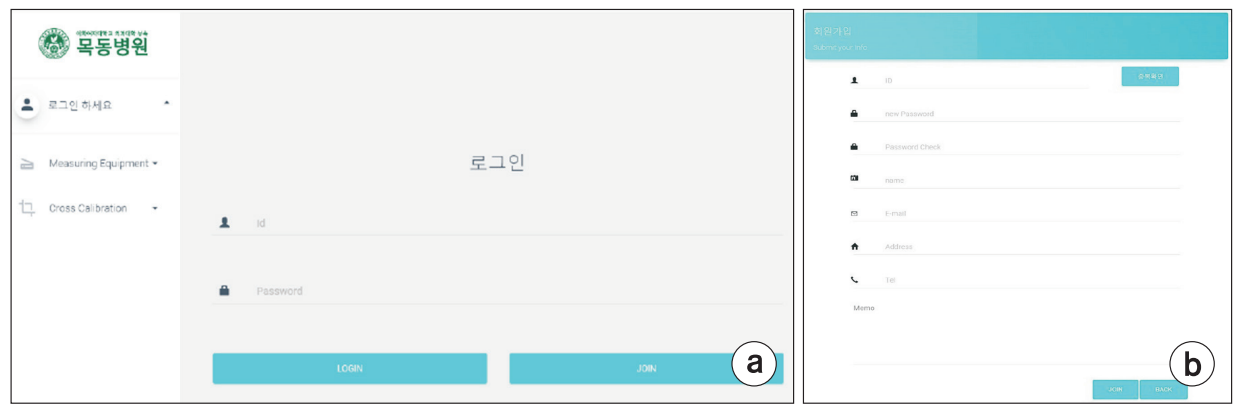

Fig. 3. Program form of (a) the main screen and contents list (b) the registration window.

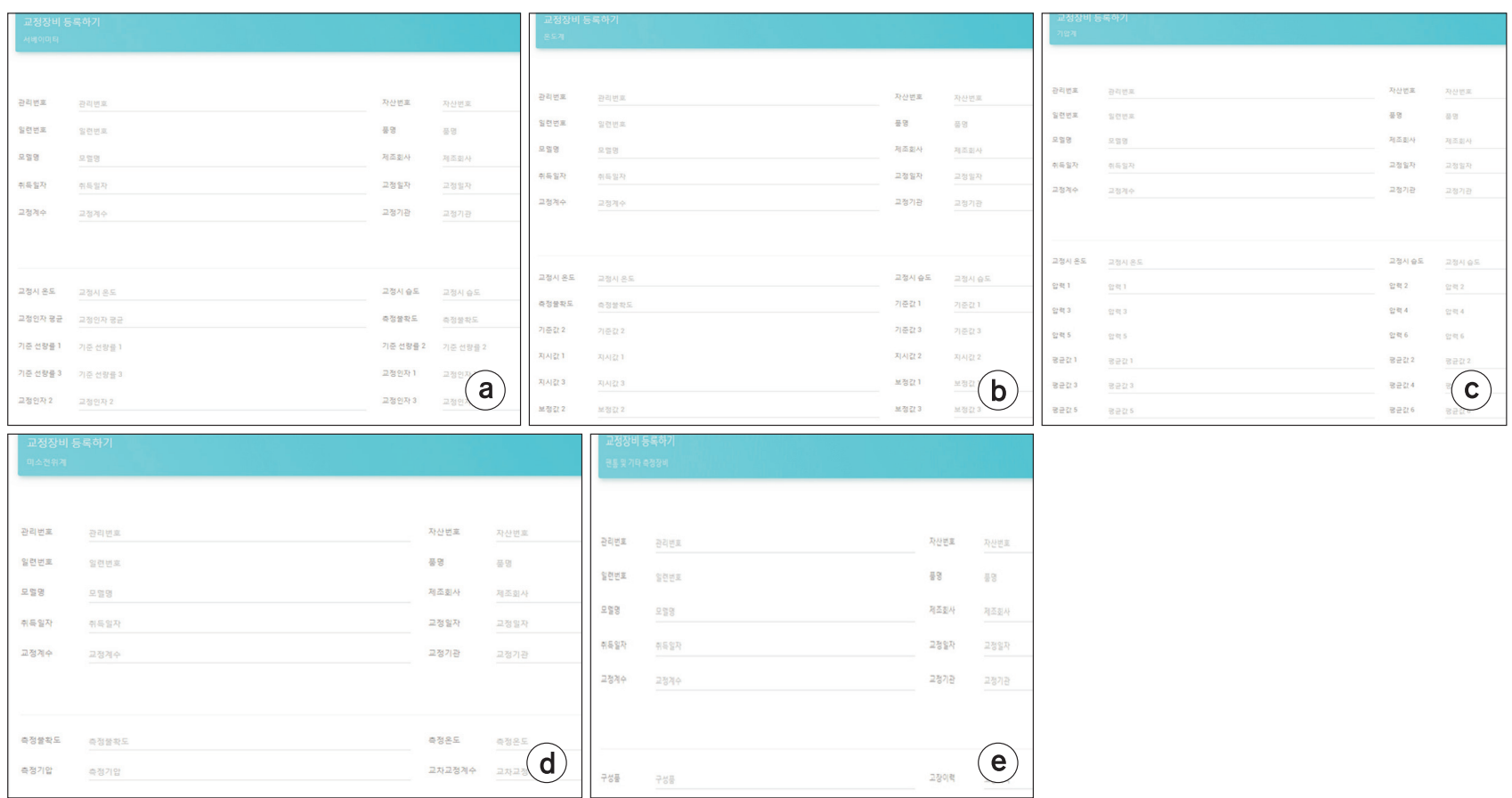

Fig. 5. The registration sessions for (a) survey meter, (b) thermometer, (c) barometer, (d) electrometer, and (e) phantom and etc. 
Where, $\left(\overline{\mathrm{M}}_{\mathrm{c}}\right)_{\text {ref }}$ and $\left(\overline{\mathrm{M}}_{\mathrm{c}}\right)_{\text {field }}$ are the mean of the values at the top and bottom position of the phantom for field and reference ionization chambers, respectively. $\left(\mathrm{N}_{\mathrm{D}, \mathrm{W}}^{60_{\mathrm{C}}}\right)_{\text {field }}$ and $\left(\mathrm{N}_{\mathrm{D}, \mathrm{W}}^{60_{\mathrm{W}}}\right)_{\text {ref }}$ are the absorbed-dose-to-water calibration factor for the field and reference chambers. $\left(\mathrm{k}_{\mathrm{Q}}\right)_{\text {ref }}$ and $\left(\mathrm{k}_{\mathrm{Q}}\right)_{\text {field }}$ are quality factors.

In this study, the cross calibration factor was defined by the ratio between $\left(\overline{\mathrm{M}}_{\mathrm{c}}\right)_{\text {ref }}$ and $\left(\overline{\mathrm{M}}_{\mathrm{c}}\right)_{\text {field }}$.

\section{Results and Discussion}

The web-based program was developed to facilitate the maintenance by simplifying the complex cross calibration by constructing the data of the measurement instrument in the clinical site. The program was designed to access the program through subscription so that the list of instrument can be managed by each user or organization. After creating account, user can easily access with his/her ID and PW on the main screen as shown Fig. 3a. Through the whole view, it was made easy to figure out the status of the measurement instrument possessed by each institution and to maintain the records in Fig. 3b.

Fig. 4 shows the session for registering calibration and recording instrument in the program. Registered instruments

Table 1. Common list for measurement equipment

\begin{tabular}{ll} 
Management number & Asset number \\
Serial number & Name of goods \\
Model name & Manufacturer \\
Acquisition date & Calibration date \\
Calibration factor & Calibration institution \\
\hline
\end{tabular}

were classified as ionization chamber and detector, survey meter, thermometer, barometer, electrometer, phantom, and other instrument according to their use and management characteristics. The registration session of ionization chamber includes the basic information with the management number and serial number. And also, information of ionization chamber includes the diameter and operating voltage that should be considered when measuring doses to enhance program usability. In the lower section, a calibration report issued by an accredited calibration laboratory or user institution can be attached as a PDF file. There are other additional functions to browse the list and to add pictures of the instrument for easy management. In Fig. 5, Table 1, and Table 2 show the detail information of each instrument.

Fig. 6 shows the cross calibration session. In the first step of cross calibration, the date and instrument for cross calibration are selectable though the management number. In

Table 2. Each list for measurement equipment

\begin{tabular}{|c|c|}
\hline Equipment & List \\
\hline $\begin{array}{l}\text { Ionization } \\
\text { chamber }\end{array}$ & $\begin{array}{l}\text { Measurement uncertainty, temperature, pressure, } \\
\text { voltage, diameter of ionization chamber, } \\
\text { calibration factor }\end{array}$ \\
\hline $\begin{array}{l}\text { Survey } \\
\text { meter }\end{array}$ & $\begin{array}{l}\text { Measurement uncertainty, temperature, pressure, } \\
\text { average calibration factor, reference dose rates, } \\
\text { calibration factor }\end{array}$ \\
\hline $\begin{array}{l}\text { Thermo- } \\
\text { meter }\end{array}$ & $\begin{array}{l}\text { Measurement uncertainty, temperature, pressure, } \\
\text { reference value, corrected value, reading value }\end{array}$ \\
\hline Barometer & $\begin{array}{l}\text { Calibration temperature, calibration pressure, } \\
\text { measurement pressure, reading pressure }\end{array}$ \\
\hline $\begin{array}{l}\text { Electro- } \\
\text { meter }\end{array}$ & $\begin{array}{l}\text { Measurement uncertainty, temperature, pressure, } \\
\text { calibration factor }\end{array}$ \\
\hline Phantom etc. & Composition, calibration history \\
\hline
\end{tabular}

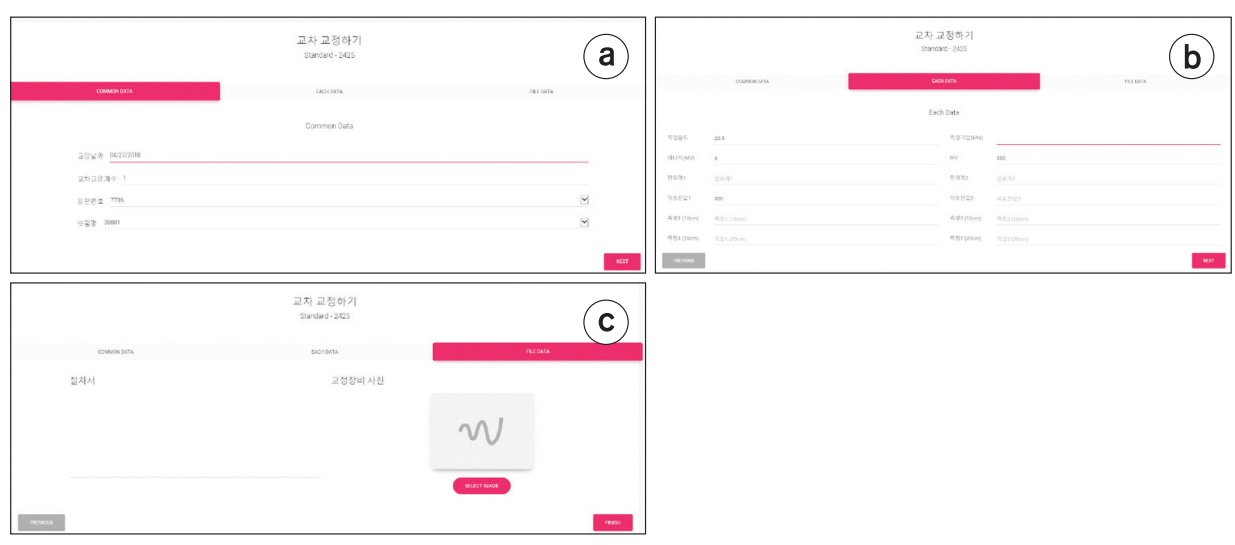

Fig. 6. Step session for cross-calibration procedure. (a) common data, (b) each data, and (c) file data. 
the second step, the temperature and pressure at the time of measurement and the reading values of each ion chamber at two depths are recorded. In the FILE DATA session, the calibration procedure and the final results for the certification are recorded.

\section{Conclusion}

The department of radiation oncology has a lot of information of radiotherapy machines, and various radiation measurement instruments. Recording and management of them are also closely related to efficient and accurate radiation therapy. Although automated recording and management of patient information such as electronic medical records (EMR) system has been used in most hospitals, databases and management systems for radiation measurement instrument are not use by every institutions. ${ }^{7-9)}$

The web-based program for the recording of the radiation measurement instrument developed in this study is advantages in that the user can easily input information and trace it according to the instrument. The program can be also accessed anywhere because it is based on the web. In addition, it is advantageous that the ion chamber can be more easily managed for the cross calibration.

\section{Acknowledgements}

This research was supported by Basic Science Research Program through the National Research Foundation of Korea (NRF) funded by the Ministry of Education, Science and Technology (No.2015R1D1A1A01060463 and No.2013R1A1A2012013) and the Radiation Safety Research Programs (1305033) through the Nuclear Safety and Security Commission.

\section{Conflicts of Interest}

The authors have nothing to disclose.

\section{Availability of Data and Materials}

All relevant data are within the paper and its Supporting Information files.

\section{References}

1. Han Yy, Huh SJ, Ju SG, Ahn YC, Lim DH, Lee JE, Par W. Impact of an electronic chart on the staff workload in a radiation oncology department. Jpn J Clin Oncol. 2005;35(8): 470-474.

2. Lee DH. The development of medical information management system of radiation oncology department. Journal of the korea institute of maritime information \& communication sciences. 2010;14(3):655-662.

3. Absorbed dose determination in external beam radiotherapy: An international code of practice for dosimetry based on standards of absorbed dose to water. IAEA TRS398 2006;12:1-183.

4. Klein EE, Hanley JS, Bayouth J, Yin FF, Simon W, Dresser S, Serago Ch, Aguirre F, Ma LJ, Arhomandy BJ, Liu Ch. Task group 142 report: quality assurance of medical accelerators. Am. Assoc. Phys. Med. 2009;36(9):4197-4212.

5. Kutcher GJ, Coia L, Gillin M, Hanson WF, Leibel S, Morton RJ, Palta JR, Purdy JA, Reinstein LE, Svensson GK, Weller M, Wingfield L. Comprehensive QA for radiation oncology: report of AAPM radiation therapy committee task group 40. Med. Phys.1994;21(4):581-618.

6. Serré L. Transfer of ionization chamber calibration coefficients in linac MV x-ray beams. 2008:1-123.

7. Scott LS, Joel ET, Larry MM, Julian GR, Edward LC. RAPID: An electronic medical records system for radiation oncology. Seminars in Radiation Oncology. 1997;7(1):4-10

8. John AK, Aleksandra Z, Jeffery S, Paul F, Vythialingam S, Cynthia B, Alfred WR, Nick R, Bharat BM. A comprehensive quality assurance program for personnel and procedures in radiation oncology: value of voluntary error reporting and checklists. Int J Radiat Oncol Biol Phys. 2013; 86(2):241-248.

9. Lawrence BM, Marianne J, Liyi X, Sha XC, Katharin DB, Lukasz M, Ellen LJ, Patricia S, Dana L, Dee CB, Robert DA. Practical Radiation Oncology. 2011;1:2-14. 